\title{
AN INTEGRATED MODEL OF TEAM MOTIVATION AND WORKER SKILLS FOR A COMPUTER-BASED PROJECT MANAGEMENT SIMULATION
}

\author{
Wee-Leong Lee \\ Singapore Management University \\ School of Information Systems \\ 80 Stamford Road \\ SINGAPORE 178902
}

\begin{abstract}
In this paper, I shall propose an integrated model of worker skills and team motivation for a computerbased simulation game that can be used to provide experiential learning to students. They can act as project managers here without being burdened by the costs and risks associated with unsuccessful projects. I shall present an approach of classifying skills into five different types (relevant to IT projects) and apply a five-point competency scale to each skill type. The Pearson Correlation will be applied to the scores of each skill type to generate an efficiency index that will characterize the effectiveness of a team working on a task. I shall also describe a model to represent the relationship between the social needs of team members and their motivation levels. The results of the actual simulation games will be presented here followed by a discussion on the practical implications and recommendations.
\end{abstract}

\section{INTRODUCTION}

In an earlier paper (Lee 2011), I introduced a computer-based simulation game that I had created and used as an effective teaching tool for project management courses. While the game can be played alone or in a group, I prefer the latter in order to encourage an exchange of ideas and promote discussion. The game entrusts the participants with planning and managing an IT project. The project consists of a set of tasks that need to be completed and the participants are 1. required to create a project plan and 2. execute it. The project plan consists of a Gantt Chart, a network diagram, and an optional training plan. During the execution phase, it is imperative that diverse events and situations will emerge and participants will be required to exercise their judgment in making the right decisions to steer the project towards completion. Participants will also be required to plan project reviews, quality reviews, meetings with team members, and organize social outings. These activities will impact the project schedule, cost, quality, and team motivation. In this paper, we shall discuss the modeling of motivation, both, at the individual level as well as the team level and examine how it can be influenced by the actions of the project manager.

Motivating the team is a crucial responsibility of the project manager. There is a higher possibility of failure in the absence of a motivated team. Having a project team that reports punctually, enjoys the work involved, communicates well with everyone, offers support when needed, and maintains a positive attitude implies a better chance at completing the project within the budget, on schedule, and to customer satisfaction. A project team that is unmotivated, displays poor attitudes and shows a marked lack of interest in the task. The outcome may also not be as successful as expected.

Thoms (1998) describes three stages of the project lifespan in terms of motivation of the project team. In the early stage of the project, the goal is to set up the team. Each individual member is excited and motivated about the project so the momentum is easily built up. In the middle stage, as the project develops, the team is bogged down by the details of the day-to-day work. The problems emerge and motivation levels begin to fall. By the final stage, the team members look worn-out and bored with technical details, and get anxious about the next project. Motivation levels at this stage may drop even further. In general, most project teams start off with a high motivation level but as the project progresses, the motivation level is 
likely to decline and if this is not addressed, the project runs into trouble. A key role of the project manager is to motivate the project team throughout the project lifecycle.

The rest of this paper is organized as follows: Section 2 presents a brief literature review of the workers' motivation. Section 3 presents a simple model of workers' skills and introduces the expertise model. Section 4 presents a model that describes team motivation. Section 5, presents and analyzes a set of simulation results. Section 6 concludes the paper.

\section{LITERATURE REVIEW}

The project team's motivation level and overall morale can significantly impact project performance. Project managers can motivate team members by soliciting their inputs, suggestions, help in developing solutions, and making decisions. Understanding team members' work ethics and attitudes regarding the project may be critical to achieving success too. Douglas McGregor (1960) classified personalities into Theory X and Theory Y. Knowing and understanding the differences between Theory X and Theory Y employees can help project managers address personality types accordingly. Brenner (2007) addresses the issue of employees' motivation by considering the impact of having both Theory X and Theory Y personalities in the project team. Theory Y personality employees tend to report to be punctual, self-motivated, committed to work, do things without being asked, enjoy what they do, and therefore, get the work done. Theory X personality employees, on the other hand, are often late to work, have very little motivation to execute their responsibilities, and constantly need to be told what to do.

Training is necessary to enhance employee performance; trained employees are better aware of their job specifications, have better skills to perform the job well, and work with high motivation levels leading to optimal performance. Khan (2012) studies the impact of training and motivation on employee performance. He defines performance as a function of training and motivation and assigns a coefficient to each. Basing his theory on the Pearson Correlation analysis, he finds a correlation between training and motivation and concludes that if employees are provided adequate training, they will perform better. Teasley et al. (2012) on the other hand, explore the interactive effect of both, training and technology policy along with task significance on the effectiveness of employees in project and technology management. Their survey suggests that engineers and technically trained individuals sometimes lack effective people skills and managers should then compensate these deficiencies by offering adequate intrinsic support to enhance the overall satisfaction of their employees. Rothenberg (2011) studies the effect of team composition based on pre-decision information about productivity on the ability of performance measurement systems to promote cooperation when agents' efforts are subject to moral hazards. He identifies those group incentives which promote cooperation and are preferred to individual incentives which promote competition between agents.

Through the classical theories of human motivation, we know that work motivation has been characterized by dimensions such as, secured and interesting jobs, ability to perform the job, recognition from supervisors and colleagues, adequate pay, and feedback on performance. The classical theories work very well with the individual employee but may not consider the complexities of dealing with a group whose members have diverse backgrounds, personalities, and skill levels. Over the last decade, issues of work motivation in relation to groups and teams have been gaining significant attention. As a result, constructs such as "shared identity", "need for relatedness", "cohesiveness", and "communications" have been suggested and discussed widely by many researchers (Dwivedula and Bredillet, 2010). In project management, goal clarity is seen as having a crucial influence on work motivation as have feedback on performance and communication between the project team members and their manager (Turner 2003). In this paper, I discuss a model that simulates the effects of team motivation and examine its impact on the performance of a project in the setting of a project management gaming environment.

\subsection{Skills improvement and deterioration model}

The Theory of Learning Curve states that the time needed to produce a unit of an item decreases with the experience of processing additional units, often, with diminishing returns on additional returns. As an ex- 
tension of this line of reasoning, forgetting may be viewed as the decay of productivity during breaks in practical experience. A power function is commonly used to represent the learning curve that establishes an exponential relationship between time and the number of units processed. Azizi et al. (2010) generalizes the leaning and forgetting phenomena by establishing the relationship between the number of times a worker performs a particular task and his skill improvement. As such, they suggest skill improvement (or learning) can be measured as an increasing function while skill deterioration (or forgetting) can be measured by a decreasing function. The rate of change for both, the increasing and decreasing functions can be represented by an exponential function as shown in Figure 1.

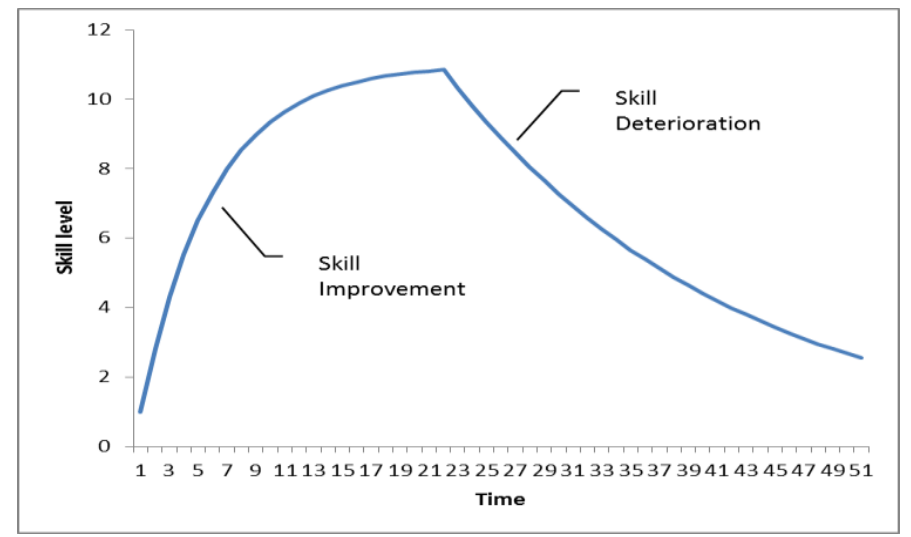

Figure 1: Skill improvement and deterioration

The skill improvement formula can be represented as

$$
S=\left(S^{\max }-S^{R}\right) e^{\beta t}
$$

where $S$ is the skill level of worker, $S^{\max }$ is a theoretical maximum level of skill, $S^{R}$ is the remnants of workers skill which was gained by performing the task in the past, $\beta$ is the learning slope of the worker and $t$ is time.

The skill deterioration formula can be represented as

$$
S=S^{R} e^{\alpha t}
$$

where $\alpha$ is the forgetting slope of the worker.

In the project management simulation game, I simulate the rise and fall in motivation levels of the team similar to the skill improvement and deterioration model described above.

\section{THE WORKER'S SKILLS AND EXPERTISE MODEL}

In the simulation game, I apply a simple formulation to model workers' skills and abilities by classifying skills into different types and within each type, establish a scale of 1 to 5 to represent their abilities ( 1 being the lowest and 5 the highest). The project tasks are modeled using the same matrix of skills. A formulation will be applied between the workers and the project tasks to compute an efficiency index that would affect the time taken for a worker or a team to complete the assigned task. In doing so, I assume that worker or team productivity is specific to the task and is a function of the skills the worker possesses.

A project consists of a series of interconnected tasks that require people with different skills to perform. One of the greatest challenges for project managers is to match the most suitable worker or team with a particular task. Availability is a consideration apart from matching skill sets. Project managers need to be able to evaluate the strengths and weaknesses of their project teams and this is normally judged through interviews or past experiences of working on other projects. Experienced project managers tend to be able to tell the type of skills needed to perform a specific task. For instance, if the requirement is for someone who can gather information well, it would be imperative to select a candidate with a good understanding of business processes and domain knowledge rather than someone with strong programming and database design skills. 
In the simulation, this matching between the resource and task is undertaken by comparing the numerical representation of skills between the workers and task. To illustrate, Table 1 shows the numerical representations of a range of skill requirements for a task along with three resources (workers). Resource A is stronger in technical skills but weaker in business process skills thus not suitable for the task which requires someone who is strong in business process skills and has good human relations skills. Resources B and $\mathrm{C}$ on the other hand, are stronger in those areas and therefore, better suited to the task.

Table 1: Quantitative representation of skills for task and resources

\begin{tabular}{c|ccccc}
\hline & Web Design & Database & Coding & Business Processes & Soft Skill \\
\hline Task & 2 & 2 & 2 & 5 & 3 \\
Resource A & 3 & 5 & 4 & 2 & 1 \\
Resource B & 1 & 2 & 1 & 5 & 4 \\
Resource C & 2 & 1 & 2 & 3 & 5 \\
\hline
\end{tabular}

We need a method to evaluate this set of values to determine how well they match each other. A simple approach is to compute the sum and average across the different skills for both, the task and resources. With reference to Table 2, both, the average and sum yield the same outcomes; all three resources are found suitable for the task based on the absolute differences between the task and resource skills. This method ignores the emphasis given to each skill component and thus, is not a suitable model for the simulation.

Table 2: Computed values for average and sum

\begin{tabular}{c|cccc}
\hline & Average & $\begin{array}{c}\text { Absolute } \\
\text { diff }\end{array}$ & sum & $\begin{array}{c}\text { Absolute } \\
\text { diff }\end{array}$ \\
\hline Task & 2.8 & & 14 & \\
Resource A & 3 & 0.2 & 15 & 1 \\
Resource B & 2.6 & 0.2 & 13 & 1 \\
Resource C & 2.6 & 0.2 & 13 & 1 \\
\hline
\end{tabular}

Since it is important that the skill types are compared against each other, we evaluate the correlation between the two sets of values. A popular model that measures this correlation is the Pearson ProductMoment Correlation Coefficient which measures the correlations between two independent variables $\mathrm{X}$ and $\mathrm{Y}$, giving a value from -1 (indicating perfect negative association) to 0 (no association) to +1 (perfect positive association). The Pearson function is widely used as a measure of the strength of linear dependence between two variables. The Pearson Coefficients between the task and resources A, B, and C are presented in Table 3. I normalized the Pearson Coefficients to between 0 and $100 \%$ given the values of $20 \%, 95 \%$, and $73 \%$ for resources A, B, and C, respectively. Based on this evaluation, resource B seems the most suitable resource for the task, followed by resources $\mathrm{C}$ and $\mathrm{A}$. This outcome not only matches the visual inspection method but can precisely identify the slightly better candidate from between $\mathrm{B}$ and $\mathrm{C}$ which may not be immediately obvious through the visual inspection method.

Table 3: Pearson function giving divide by zero error

\begin{tabular}{c|ccccccc}
\hline & $\begin{array}{c}\text { Web } \\
\text { Design }\end{array}$ & Database & Coding & $\begin{array}{c}\text { Business } \\
\text { Processes }\end{array}$ & $\begin{array}{c}\text { Soft } \\
\text { Skill }\end{array}$ & $\begin{array}{c}\text { Pearson } \\
\text { Coefficient }\end{array}$ & Normalized \\
\hline Task & 2 & 2 & 2 & 5 & 3 & & \\
Resource A & 3 & 5 & 4 & 2 & 1 & -0.606339063 & $20 \%$ \\
Resource B & 1 & 2 & 1 & 5 & 4 & 0.907730711 & $95 \%$ \\
Resource C & 2 & 1 & 2 & 3 & 5 & 0.455149564 & $73 \%$ \\
\hline
\end{tabular}

When the task and resource skills' values match exactly; the Pearson Coefficient is 1 representing a $100 \%$ match. If either of the task or resource skills contain identical values across the different skill types, the Pearson function will reveal a zero error (See Table 4). To overcome this limitation, the initial setting 
in the simulation will not contain identical values across different skill types. If a range of identical values is detected, a very small increment $(\sim 0.001)$ will automatically be added to the first value. This will prevent the zero error from occurring without affecting the outcome of the evaluation.

Table 4: Limitation of Pearson coefficient method

\begin{tabular}{|c|c|c|c|c|c|c|c|}
\hline & Web Design & Database & Coding & $\begin{array}{c}\text { Business } \\
\text { Processes }\end{array}$ & $\begin{array}{l}\text { Soft } \\
\text { Skill }\end{array}$ & $\begin{array}{l}\text { Pearson Coef- } \\
\text { ficient }\end{array}$ & Normalized \\
\hline Task & 2 & 2 & 2 & 2 & 2 & & \\
\hline Resource A & 2 & 2 & 2 & 5 & 3 & \#DIV/0! & \#DIV/0! \\
\hline & Web Design & Database & Coding & $\begin{array}{c}\text { Business } \\
\text { Processes }\end{array}$ & $\begin{array}{l}\text { Soft } \\
\text { Skill }\end{array}$ & $\begin{array}{l}\text { Pearson Coef- } \\
\text { ficient }\end{array}$ & Normalized \\
\hline Task & 2 & 2 & 2 & 5 & 3 & & \\
\hline Resource A & 2 & 2 & 2 & 5 & 3 & 1 & $100 \%$ \\
\hline Resource B & 2 & 2 & 2 & 2 & 2 & \#DIV/0! & \#DIV/0! \\
\hline
\end{tabular}

This approach can be easily extended to consider multiple resources working as a team. By ignoring the impact of personality traits on team effectiveness, we can model team effectiveness solely based on the combination of skills and the expertise of team members. In the simulation, I assume that if we have a team with similar skills and expertise that matches the requirements of the task, we should have higher team efficiency. On the other hand, if we have a team with diverse skills and expertise that does not quite match the requirements of the task; we may not expect the team to perform as effectively. In practice, we often get a team with a mixture of both, experienced and less experienced members. It can be viewed as the experienced members having to spend a part of their time guiding the less experienced members resulting in less time spent working on the project. Simply, put, it resembles an averaging effect of the team members' skills and expertise. After some trials with the averaging method, I found it to be adequate for modeling the combined skills of the team members in the game. Table 5 shows instances of both, the contrasting and matching skills within a team together with the computed Pearson Coefficient. In the game, students do not see the Pearson Coefficient but notice its impact on time taken to complete a task which is discussed in the next section.

Table 5: Contrasting and matching skills in a team

\begin{tabular}{c|ccccccc}
\hline & Web Design & Database & Coding & $\begin{array}{c}\text { Business } \\
\text { Processes }\end{array}$ & $\begin{array}{c}\text { Soft } \\
\text { Skill }\end{array}$ & $\begin{array}{c}\text { Pearson } \\
\text { Coefficient }\end{array}$ & $\begin{array}{c}\text { Normalized } \\
\text { Pearson } \\
\text { Coefficient }\end{array}$ \\
\hline Task & 2 & 2 & 2 & 5 & 3 & & \\
Resource A & 3 & 5 & 4 & 2 & 1 & -0.606339063 & $20 \%$ \\
Resource B & 1 & 2 & 1 & 5 & 4 & 0.907730711 & $95 \%$ \\
Average & 2 & 3.5 & 2.5 & 3.5 & 2.5 & 0.514495755 & $76 \%$ \\
Resource B & 1 & 2 & 1 & 5 & 4 & 0.907730711 & $95 \%$ \\
Resource C & 2 & 1 & 2 & 3 & 5 & 0.455149564 & $73 \%$ \\
Average & 1.5 & 1.5 & 1.5 & 4 & 4.5 & 0.77122565 & $89 \%$ \\
\hline
\end{tabular}

\subsection{Effects of team efficiency on task time}

In the simulation game, a series of project tasks need to be performed to successfully complete the project. Each task has a standard task time and a recommended number of staff that can be assigned. The actual time taken to complete each task depends on the team's effectiveness and the number of staff assigned. The efficiency index (normalized Pearson Coefficient) reflects the team's effectiveness which is inversely proportional to the time taken to complete the task. The higher the efficiency index, the less time taken to complete the task. For instance, if the efficiency index is $95 \%$ and the standard task time is 5 
minutes, the actual time taken to complete the task is 5.26 minutes $(5 / 95 \%)$. If the efficiency index is $100 \%$, the actual time taken will be 5 minutes.

Besides the efficiency index, the number of staff also contributes to the team's effectiveness. If we ignore the impact of team dynamics, we can generalize that a bigger team is more likely to complete a task quicker than a smaller team. The effects of team dynamics is incorporated in another part of the game. Team members will complain (via "email" which pops up every now and then throughout the game) if the team becomes too large. If nothing is done to address their concerns, motivation levels will be affected. The effect of team size is represented by a ratio of the number of staff assigned to a particular task against the recommended number of staff for that task. The overall effectiveness of the team is computed as a product of the efficiency index and the team ratio. Table 6 shows the effects of team effectiveness with different numbers of staff in a team.

Table 6: Effects of different number of staff in a team

\begin{tabular}{c|cccc}
\hline Recommended number of resources & Team efficiency with 3 staff & 2 staff & 3 staff & 4 staff \\
\hline 3 & $88 \%$ & $59 \%$ & $88 \%$ & $117 \%$ \\
\hline
\end{tabular}

At the initial stage of the game, students are required to create an ideal project plan by assigning effective teams to each task to reduce the time taken to complete this task which will also shorten the overall project timeline. In this paper, we did not discuss the availability of workers but it was a great hindrance to the students both, in the project planning and execution phases. The constraint of staff availability was deliberately designed into the game to simulate real-life situations in which the ideal candidate for a task may not be available at the time when he or she is needed most. Simulating the scarcity of good resources not only makes the game more challenging, but also reflects the reality of project management whereby good staff are hard to come by and project managers will be competing to have them in their team.

\section{THE PROJECT TEAM MOTIVATION MODEL}

At the start of a project, the morale of the team is generally high as everyone is excited and eager to get started. As the project progresses, problems appear and disagreements between team members emerge, coupled with unrealistic expectations from clients or slow response from vendors all of which can lead to loss of motivation. Project managers have to be sensitive to the needs and issues of the project team and maintain high motivation levels. This is essential if project managers do not actively inspire or motivate the project team.

In the simulation, the motivation levels of the project team may be affected by the amount of interactions (informal chatting sessions) between the project manager and team members, the number and frequency of social outings organized, and the amount of training provided to the team members. To create pragmatism in the game, the motivation of the team is designed to decline if the project manager ignores their social needs. Motivation level is set to decline over time in a linear fashion at a rate following a uniform distribution. Engaging in informal chatting sessions with team members creates a positive effect on the motivation levels of the team. The frequency of these informal chatting sessions is the basis for computing the improvement in motivation levels subjected to the Law of Diminishing Returns. The effects of these sessions are however, programmed to last only one week. As such, in order to maintain or improve the levels of motivation within the team, project managers need to communicate regularly with their team members, and not only at the project kick-off or key milestone meetings. The effects of social outings on motivation levels is modeled in a similar fashion but the positive effects last longer; over two weeks. The social outings incur a small cost while the informal chatting sessions only take up a little of the project manager's time. The impact of training - which is not discussed in this paper - is also modeled in a similar fashion and it incurs a higher cost but has a greater impact on motivation levels.

At the start of the game, motivation levels usually start at $100 \%$ and the rate of decline follows a uniform distribution between $-1 \%$ to $2 \%$. As such, on some days team morale will be high but on most days, the morale will be low. Figure 2 shows two scenarios of a general declining trend in motivation levels 
over a period of 50 days. In the absence of any attempt by the project manager to socially engage the team, this is what team motivation will look like as the project progresses:

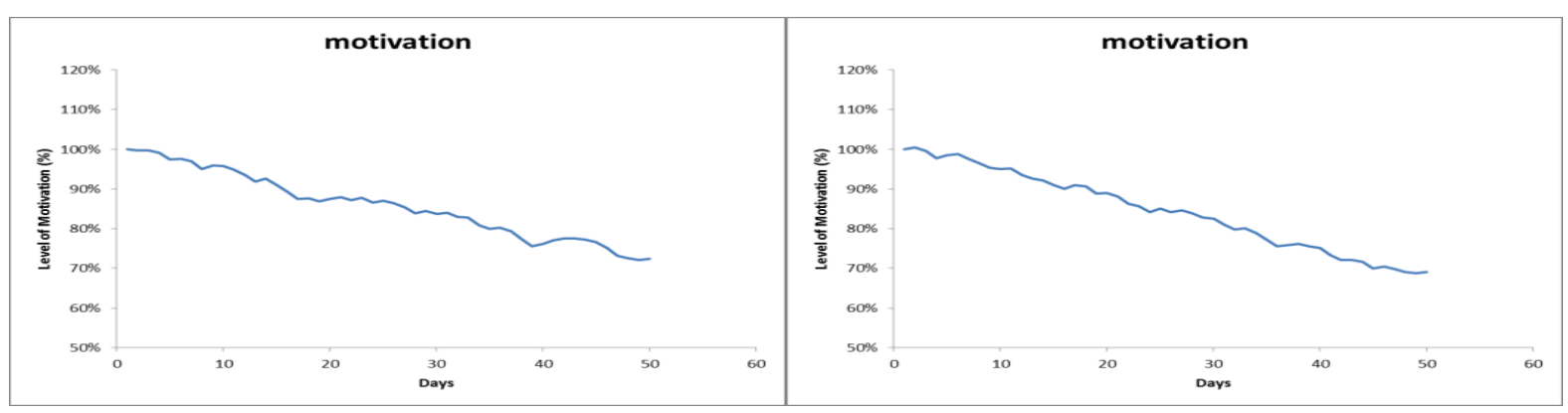

Figure 2: Drop in motivation level over time

\subsection{Effect of informal chatting sessions on motivation levels}

Informal chatting sessions increase the motivation levels by a certain amount depending on the frequency and the length of time spent by the project manager here. Looking at Figure 3, the vertical red bars represent the occurrence of informal chatting sessions. The height of the bars indicates the length of time spent during each session. Figure 3 shows four scenarios and each have four informal chatting sessions occurring at different times throughout the project with different durations for each session. From the result, it is apparent that the four informal sessions have little impact on the motivation levels regardless of the length of time the project manager has spent with his team during those sessions.

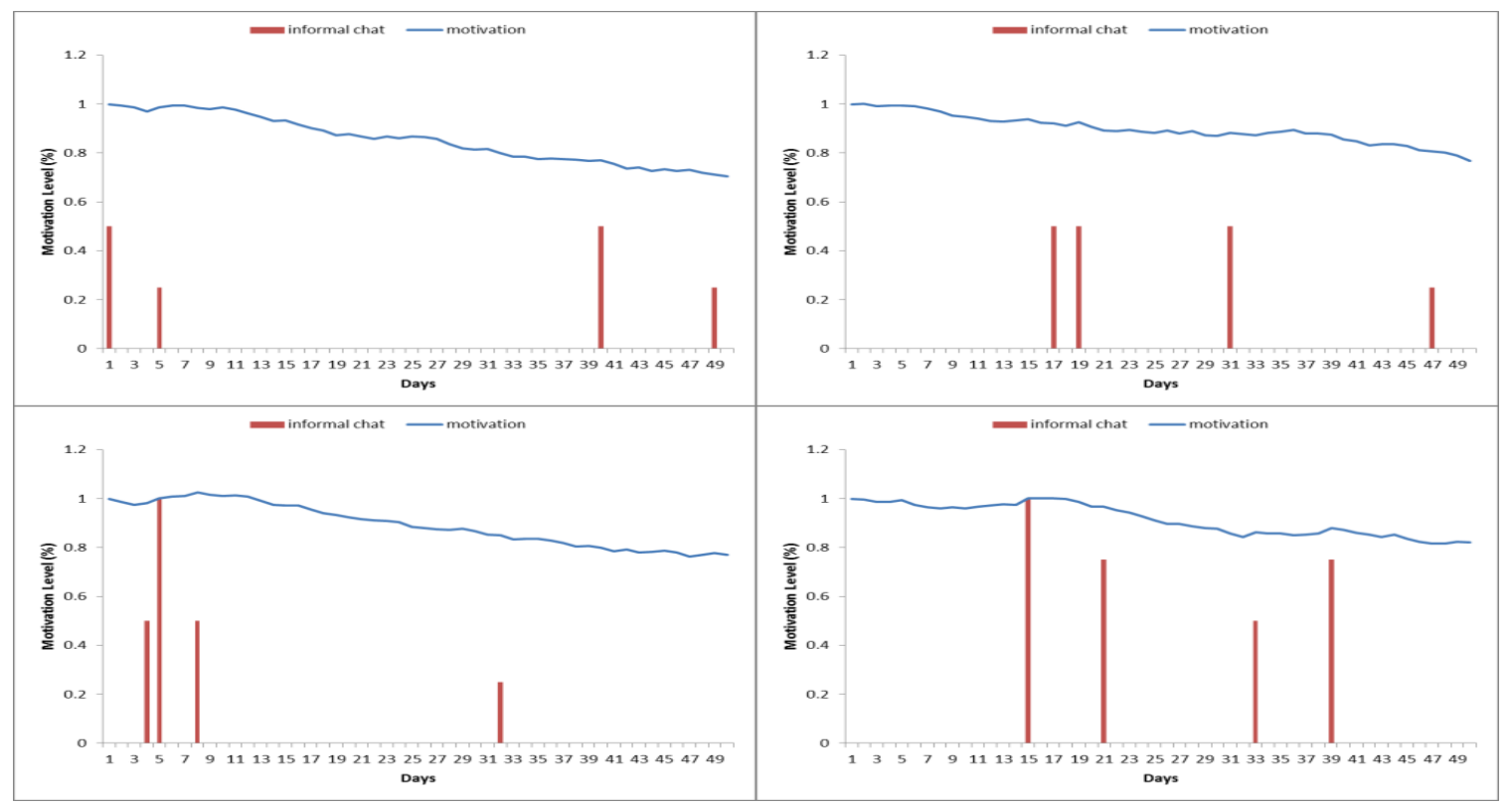

Figure 3: Impact of having four informal chatting sessions on motivation level

By simply increasing the number of informal chatting sessions to around 9 or 10 , the motivation levels may be kept quite constant throughout the project. The results in Figure 4 indicate that the duration of each session seems to have little impact on the outcome. In real-life, team members would like to see the project manager around more often as a signal that he is genuinely concerned about them and their wellbeing, and not just interested in achieving the target and driving them like slaves. Applying pressure on already unmotivated workers will adversely impact the project and kick-start an exodus of members from the team. The project manager should make an effort to get to know his team members on a personal level 
and show his appreciation for their hard work and contributions. A motivated team which respects their project manager will naturally be more devoted to perform well so as not to disappoint their manager.

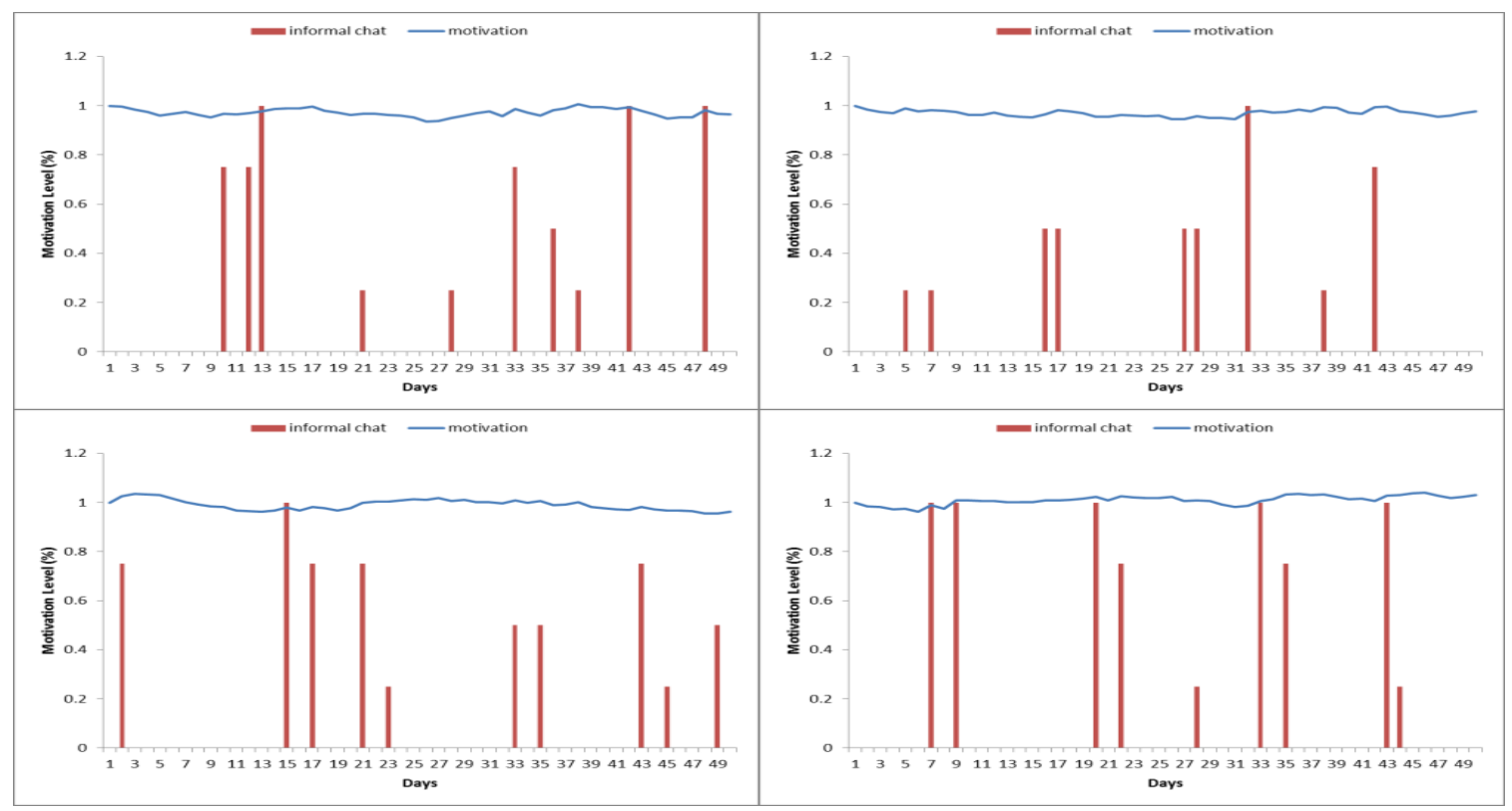

Figure 4: Impact of having 9 to 10 informal chatting sessions

Figure 5 shows that a further increase in the frequency of informal chatting sessions does not improve the motivation levels significantly. Informal chatting sessions usually take place during office hours and the project manager is responsible for a myriad tasks and cannot possibly devote all his time talking to his team members. It is the intention of the game that excessive amounts of informal chatting sessions will not improve motivation significantly. I am subjecting activities in the simulation that lead to enhancing team's motivation level to the Law of Diminishing Returns.

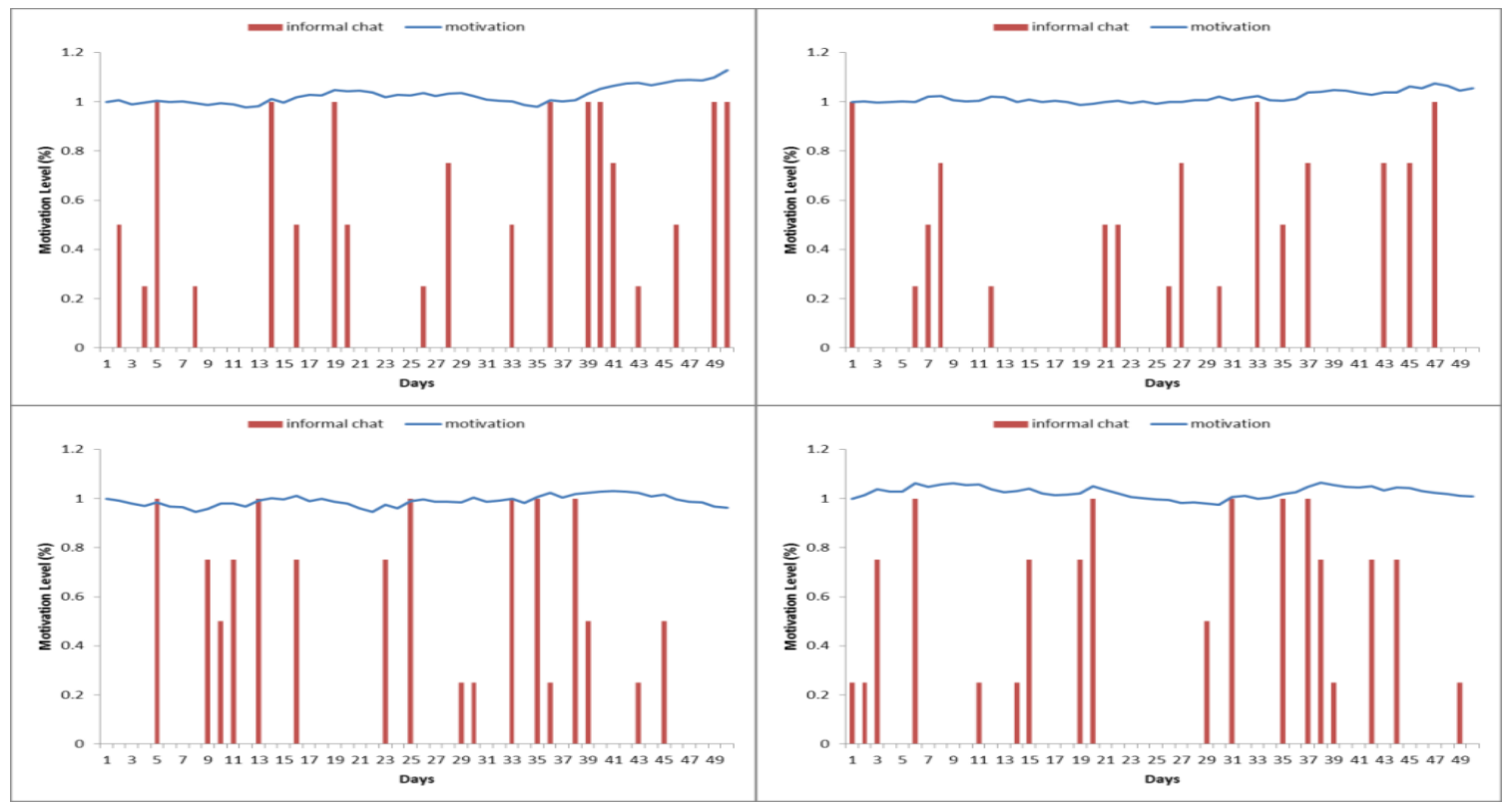

Figure 5: Impact of having 16 to 19 informal chatting sessions 


\subsection{Effects of social events on motivation level}

Social events are great opportunities to build team spirit and cohesiveness. In the simulation, the morale of team members may be immediately boosted after a social event. An exponential function akin to the skill deterioration discussed in Section 3.0 is used to simulate the drop in motivation level following a social event. In Figure 6, the red decreasing bars show the effect of a sudden increase in motivation levels after a social event that is followed by a slow exponential decline. In Figure 6, the effects of a "natural" decline in motivation levels as described in Section 3.3 have been removed. As such, without any external stimulant, the motivation levels will stay constant. In Figure 6(a), the introduction of a social event on day 7 results in an increase in the motivation level which is sustained over a period of two weeks. The motivation line was flat until day 7 before gradually increasing over 2 weeks after which it stays flat again. Figure 6 (b) shows two social events being introduced which correspond to the increase in motivation level.

In Figure 6(c), the timing of two social events occurring close together results in an overlapping effect which increases the level of motivation even further after the second event. Before the motivational effect of the first social event is completely lost, another social event occurs and the compounded motivational effect of the second social event is represented by the tall bar on day 9. The residual effect of the first event wears off after day 19 which causes a sudden drop in the motivational effects of the second event. Two social events held concurrently will not result in doubling the motivational effects. This will not only reflect reality but will also prevent players from abusing this feature as an easy way to improve a team's motivation levels. Figure 6(d) shows the impact of four social events and it is evidence of the fact that the effects of the first three overlapping events do not create a multiplying effect on motivation levels.

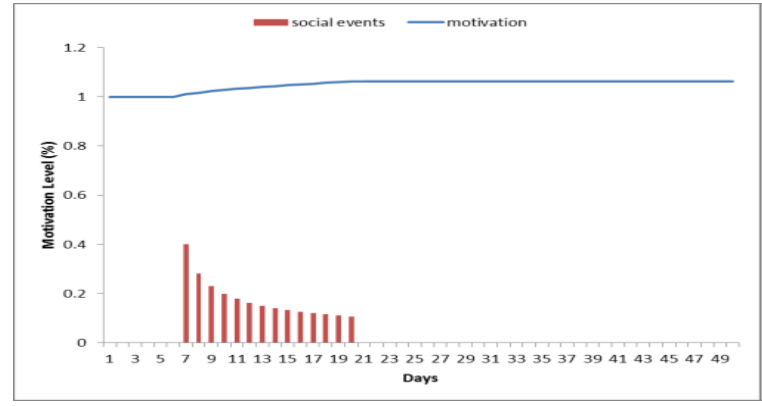

(a)

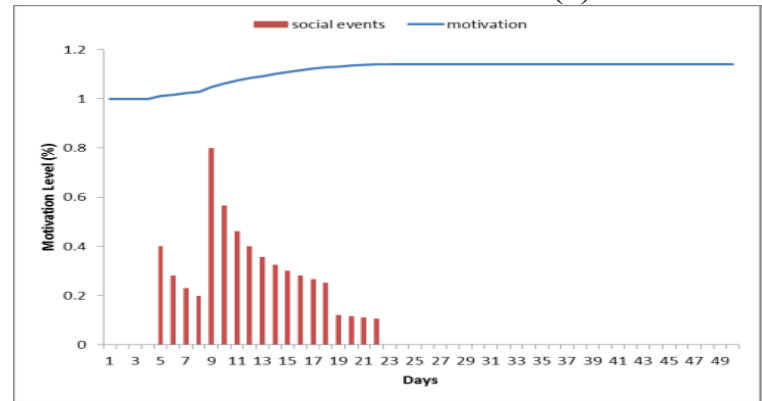

(c)

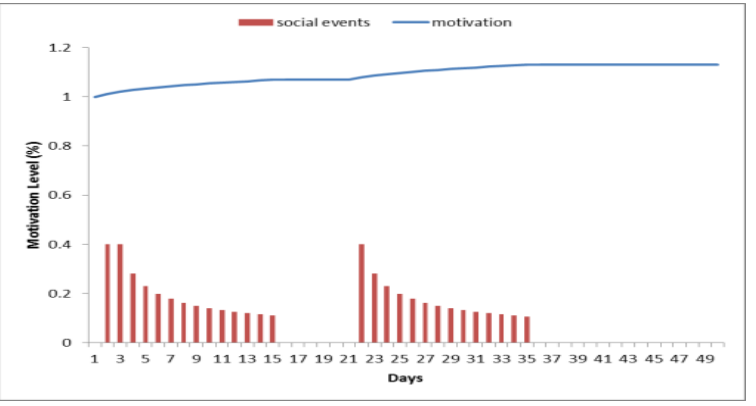

(b)

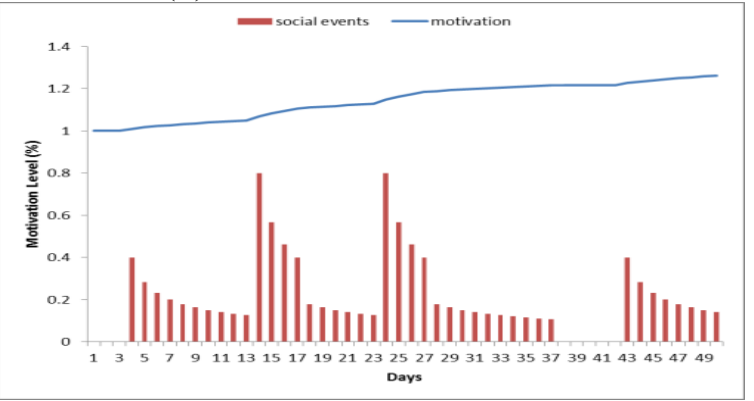

(d)

Figure 6: Decaying of motivation level

\subsection{Combine effects of informal chatting sessions and social events on motivation level}

In Figure 7, the blue line represents the motivation level, the red bars represent the occurrence and effects of social events, and the green bars below the x-axis represent the occurrence and duration of informal chats (both the red and green bars do not follow the scale on the y-axis). From the results in Figure 7, it is clear that the impact of social events is more prominent on the motivation levels than informal chats. Informal chats can retard the rate of decline but contribute little to raise motivation levels. The positive impact of social events also has a long-lasting effect. In Figures 7(a) \& (e), there is a constant decline in mo- 
tivation levels over the first two to three weeks largely attributed to the fact that the project manager rarely met up with the project team and there were no social events during that period. However, the motivation levels subsequently pick up with more informal chatting sessions and social events organized.

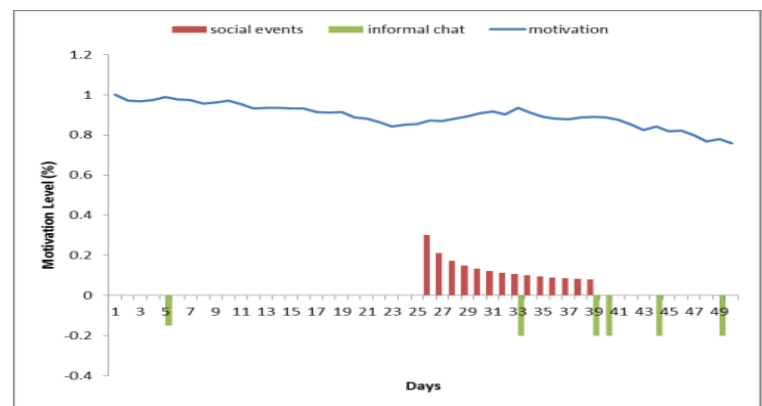

(a)

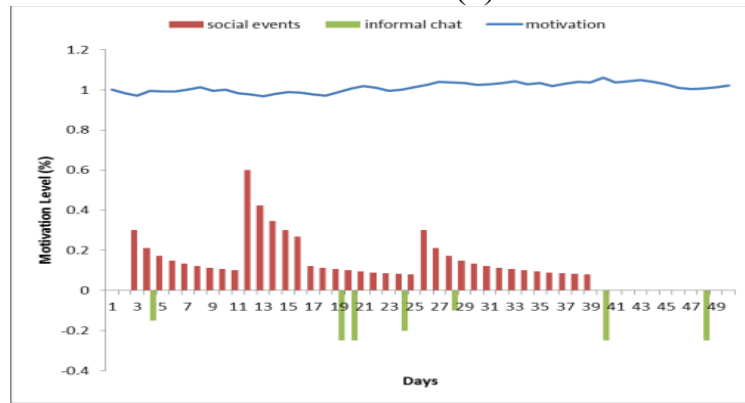

(c)

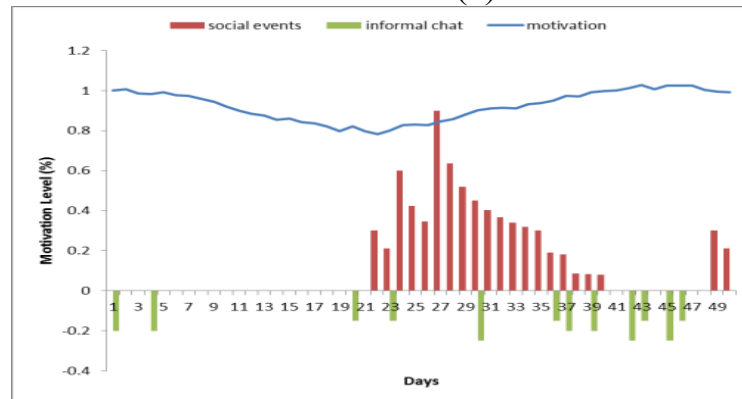

(e)

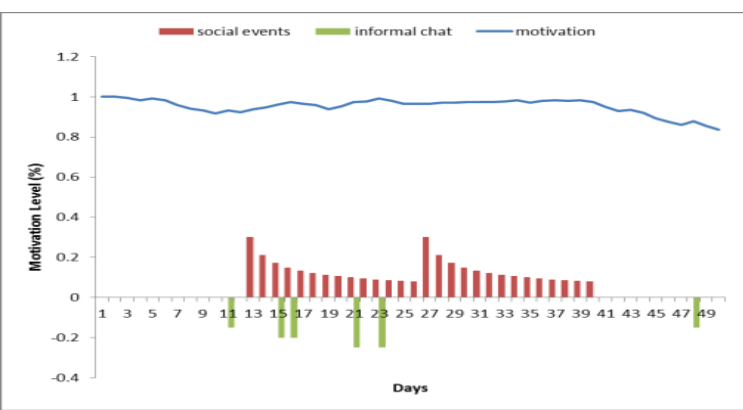

(b)

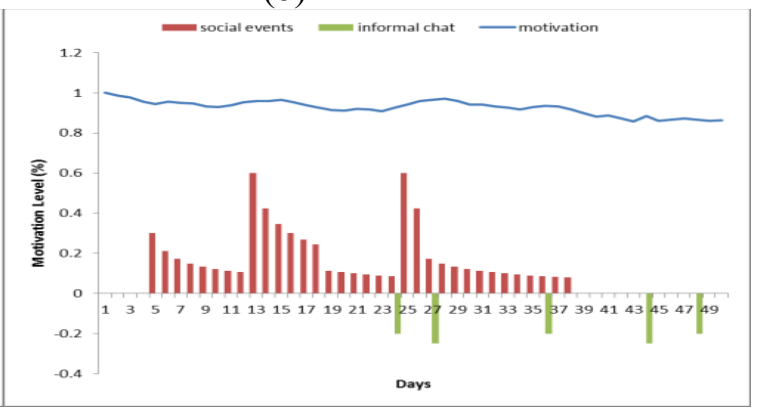

(d)

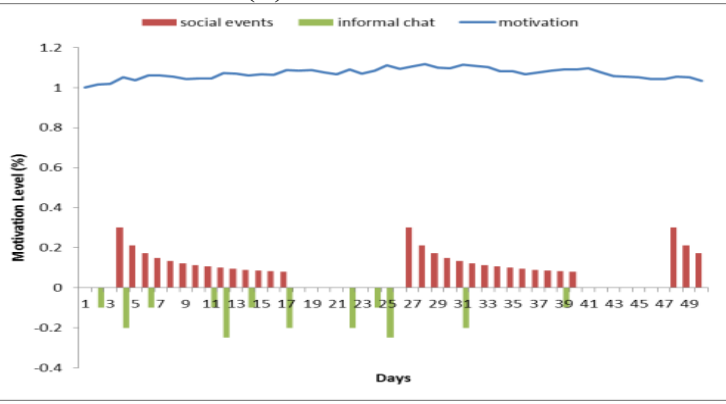

(f)

Figure 7: Combined effects of informal chatting sessions and social events

\section{SIMULATION OUTCOMES}

This simulation game was designed as a teaching tool for a post-graduate project management course. The game teaches students to appreciate the theory of project management and simultaneously, experience the complexity of project management in an intense setting as a way to promote effective learning with long-lasting effects. Students have to react to unanticipated events, make rational decisions, and perform tradeoff analysis to resolve problems in order to avoid compromising project schedule, cost, quality, or scope.

Figure 8 shows the outcomes of four games played by a group of students with two students to a group. The details of how the game is played can be found in an earlier paper by Lee (2011). The plots show the history of four performance measures (represented as percentages); project cost, project quality, motivation level, and project schedule. Project cost should be kept as low as possible: $100 \%$ is on budget, above which is cost overrun. Quality should be kept as high as possible, $100 \%$ is meeting expectation, below that is not meeting customer's expectation. Motivation level should be kept as high as possible. Pro- 
ject schedule should be as low as possible, $100 \%$ is on schedule, anything above that is considered project delay.

Throughout the game, students are allowed to modify the project plan by moving staff in and out of different tasks. From the results, it is obvious all four projects are not well managed given the high cost overruns and schedule delays witnessed, which reflect in some way, the reality of low success rate in IT projects even today. In all four cases, the project quality also suffers initially but eventually picks up and this is something which can be explained by the how the game is structured to play. The project execution stage is played in two parts; the game temporarily halts after one month of execution to allow players to reflect on their strategies and actions on the performance of the project. At that juncture, the instructor will discuss the performance of the project with students, point out the common mistakes and suggest what can be done to address poor project performance. As a result, we often see an improved performance during the second-half of the execution. It is also worth noting that motivation levels influence project quality. Project quality is modeled after real-life situations, whereby a highly motivated team is more likely to produce high quality results while a low morale team can hurt the project by producing poor quality outputs and delaying it.

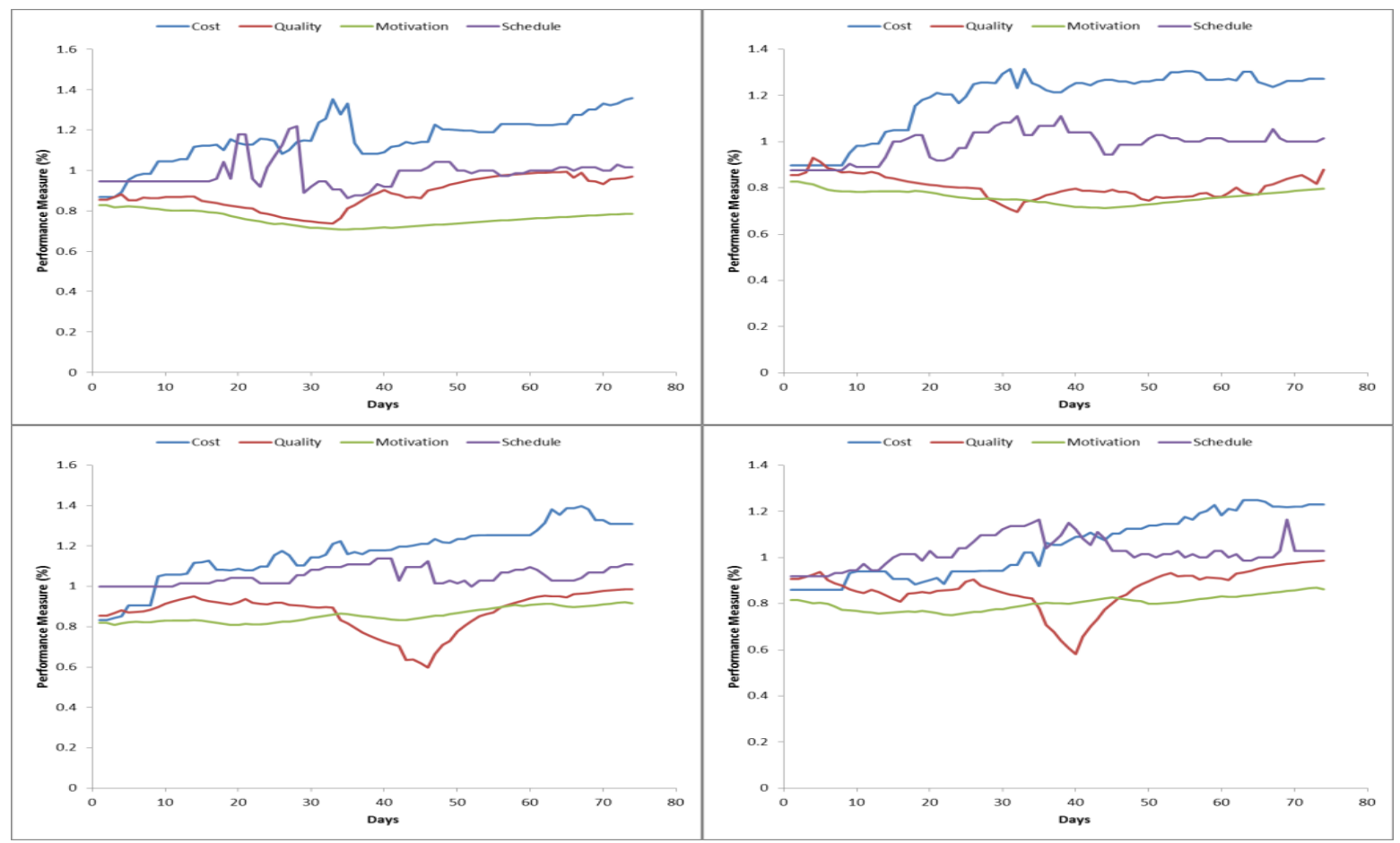

Figure 8: Simulation results

\section{CONCLUSIONS}

In this paper, I discuss how simple algorithms can be used to model the complexity of staff motivation in a team and describe how it may be implemented in a project management simulation game. The team motivation model is reflective of real-life situations in a limited way but is sufficient to display behaviors that mimic the rise and fall of motivation levels in a team. This can be observed by students whose actions in the game will be their responses to situations. The models described in this paper are not intended for comprehensive representations of the complexity of human motivation. These are specifically used within the game setting to artificially create the effects of how external stimuli such as, informal chatting sessions and social outings can play a vital role in motivating the team.

The game has been an effective teaching tool for teaching the theories and best practices of project management to both, post-graduate and under-graduate level courses at the Singapore Management Uni- 
versity with great success. It has become so popular that a large local bank has adopted it as part of their in-house training program for their graduate executive program.

\section{REFERENCES}

Azizi, N., S. Zolfaghari, M. Liang. 2010. "Modeling job rotation in manufacturing systems: The study of employees's boredom and skill variatins", International Journal of Production Economics, Vol. 123, pp. 69-85.

Brenner, D. A. 2007. “Achieving a successful project by motivating the project team”, Cost Engineering, Vol. 49, 5, pp. 16-20.

Dwivedula, R., C. N. Bredillet. 2010. "Profiling work motivation of project workers", International Journal of Project Management, Vol. 28, pp. 158-165.

Khan, M. I. 2012. "The impact of training and motivation on performance of employees", Business Review, Vol. 7, 2, pp. 84-95, July-December 2012

Lee, W. L. 2011. "Spreadsheet Based Experiential Learning Environment for Project Management”, Proceedings of the 2011 Winter Simulation Conference, Phoenix, Arizona, December 11-14.

McGregor, D. 1960. "The Human Side of Enterprise", New York, McGrawHill.

Rothenberg, N. R. 2011. "Team, leaders, and performance measures", Contemporary Accounting Research, Vol. 28, 4, pp. 1123-1140.

Teasley, R., M. Jordan, V. Sangtani. 2012. "The human side of technology project performance: effects of satisfaction, perceived technology policy, task significance and training", Academy of Information and Management Sciences Journal, Vol. 15, 2, pp. 53-72.

Thoms, P. 1998. "Project Team Motivation", chapter 20 of Project Management Handbook edited by J. K. Pinto, Jossey-Bass, 1998, p324-326.

Turner, R. J. (2000). "Projects and project management", Turner, R. J., Simister, S. J. (Eds.), Gower Handbook of Project Management, third ed. Gower, UK.

\section{BIOGRAPHY}

WEE-LEONG LEE is an Assistant Professor of Information Systems (Education) at the School of Information Systems, Singapore Management University. He obtained his BEng (Honours Class I) in Mechanical Engineering from the University of Leeds (UK), MEng from the Nanyang Technological University (Singapore), and PhD from the Imperial College London (UK). He formerly headed the R\&D department at Y3 Technologies (a supply chain solutions provider) and was responsible for developing and implementing supply chain solutions and providing consultancy in network design optimization, vehicle routing optimization and business process management. Before joining Y3, he was a Research Fellow at the Singapore Institute of Manufacturing Technology (a national R\&D institute) and was engaged in applied research activities in the areas of demand forecasting, vehicle routing optimization, loading optimization, and RFID solutions. Early in his career, he spent several years as an engineer in the oil \& gas and aerospace industries. His research interests span supply chain optimization, project management, and simulation modeling and he has published articles in academic journals and books, and presented papers at international conferences. His email address is wllee@smu.edu.sg. 